\title{
Analysis of relationship among the functional classification systems in cerebral palsy and the different types according to the Surveillance of Cerebral Palsy in Europe
}

\author{
Sergio Montero-Mendoza* and Inmaculada Calvo-Muñoz \\ Ministry of Education, Youth and Sports of the Region of Murcia (Spain), Physiotherapy Department, Catholic University of San Antonio (UCAM), Murcia, Spain
}

\begin{abstract}
This study aimed to analyse the relationship between Gross Motor Functional Classification (GMFCS), Manual Ability Classification System (MACS), Communication Function Classification System (CFCS) and Eating and Drinking Ability Classification System (EDACS) in children with Cerebral Palsy (CP) and development of a global profile of the child's role in activities of daily living. It is further intended to determine if the functional classifications present a predictive factor for one or several types of CP established by the Surveillance of Cerebral Palsy in Europe (SCPE). An observational study was developed in schools in the Region of Murcia during the months of March to June 2018. Participants included children and adolescents from 3 to 18 years of age evaluated individually under the same conditions by a physiotherapist with more than 10 years of experience and following the available manuals. A high correlation between the scales was found. Spastic unilateral CP presented a greater prognosis in the development of the functional abilities described by the functional scales. The study shows how the classification systems complement each other to provide a better description of the functional profile of children with $\mathrm{CP}$, and the four scales involve a predictive factor for some types of CP.
\end{abstract}

\section{Introduction}

Cerebral palsy (CP) defines a group of permanent, non-progressive disorders of movement control and posture, caused by a defect or injury suffered in the early stages of development of the nervous system [1]. Although the injury or primary cerebral defect is static and irreversible, the clinical pattern of presentation can change over time $[2,3]$. Disorders that characterise CP are often accompanied by other alterations (sensitivity, vision, perception), and by secondary skeletal and neuromuscular problems [4-6]. The deficiencies can limit the ability to eat, drink and swallow, with the resulting risk of respiratory problems [7-9]. CP is the most common cause of neurological disability in infancy, with a stable incidence in developed countries of 2-2.5 per 1000 live births [10].

In recent years and in clinical practice, several classification systems have been developed to describe functional abilities in children with CP. They share a series of common characteristics: 1) specifically built in a single function; 2) all based on the International Clasification of Functioning, Disability and Health (ICF), and the concepts of "activity" and "participation" are the core points of these systems. The ICF is a framework for describing and organising information related to functioning and disability. It provides a standard language and a conceptual basis for the definition and measurement of health and disability; 3) each classification describes "performance" (an individual's usual activity) rather than "capacity" (what people can do at their best); 4) all the classifications present 5 levels being mutually exclusive and represented with Roman numerals (I-V) avoiding quantitative values; 5) none of these systems represent an outcome measure or a diagnostic tool [11].

In order to describe functional abilities, several classifications have been developed to describe daily activities in terms of mobility, gross motor function, manual ability, communication and feeding, which may be affected by CP: a) Gross Motor Function Classification System (GMFCS) [12]; b) Manual Ability Classification System (MACS) [13]; c) Communication Function Classification System (CFCS) [14]; d) Eating and Drinking Ability Classification System (EDACS) [15]. Table 1 shows the levels of functional classification for children with CP.

In addition, in recent years a number of researchers have developed a new terminology to classify CP as described by the SCPE in order to monitor the incidence of $\mathrm{CP}$, providing a frame of reference for research and planning of assistance services [16-18].

$\mathrm{CP}$ is a major problem due to the disability it involves. Understanding the relationships among the four functional scales may be important for the purpose of establishing functional profiles in these children. Therefore, we propose to analyse the relationship among GMFCS, MACS, CFCS and EDACS in children with CP and to attempt to develop a global profile of the child's role in activities of daily living. On the other hand, we propose to determine if the functional classifications present a predictive factor for one or several types of $\mathrm{CP}$ established by the SCPE.

${ }^{\star}$ Correspondence to: Sergio Montero-Mendoza, Ministry of Education, Youth and Sports of the Region of Murcia (Spain), Physiotherapy Department, Catholic University of San Antonio (UCAM), Murcia, Spain, E-mail: smontero@ucam.edu

Key words: eating, communication, gross motor function, manual ability, cerebral palsy, children, adolescents

Received: February 02, 2019; Accepted: February 12, 2019; Published: February 18,2019 
Montero-Mendoza S, Calvo Muñoz I (2019) Analysis of relationship among the functional classification systems in cerebral palsy and the different types according to the Surveillance of Cerebral Palsy in Europe

Table 1. Levels of functional classification for children with CP

\begin{tabular}{|c|c|}
\hline GMFCS & $\begin{array}{l}\text { I. Walks without Limitations } \\
\text { II. Walks with Limitations } \\
\text { III. Walks Using a Hand-Held Mobility Device } \\
\text { IV. Self-Mobility with Limitations; May Use Powered Mobility } \\
\text { V. Transported in a Manual Wheelchair }\end{array}$ \\
\hline MACS & $\begin{array}{l}\text { I. Handles objects easily and successfully } \\
\text { II. Handles most objects but with somewhat reduced quality and/or } \\
\text { speed of achievement } \\
\text { III. Handles objects with difficulty; needs help to prepare and/or modify } \\
\text { activities. } \\
\text { IV. Handles a limited selection of easily managed objects in adapted } \\
\text { situations. } \\
\text { V. Does not handle objects and has severely limited ability to perform } \\
\text { even simple actions }\end{array}$ \\
\hline CFCS & $\begin{array}{l}\text { I. Effective Sender and Receiver with unfamiliar and familiar partners. } \\
\text { II. Effective but slower paced Sender and/or Receiver with unfamiliar } \\
\text { and/or } \\
\text { familiar partners. } \\
\text { III. Effective Sender and Receiver with familiar partners } \\
\text { IV. Inconsistent Sender and/or Receiver with familiar partners. } \\
\text { V. Seldom Effective Sender and Receiver even with familiar partners }\end{array}$ \\
\hline EDACS & $\begin{array}{l}\text { I. Eats and drinks safely and efficiently. } \\
\text { II. Eats and drinks safely but with some limitations to efficiency. } \\
\text { III. Eats and drinks with some limitations to safety; there may be } \\
\text { limitations } \\
\text { to efficiency. } \\
\text { IV. Eats and drinks with significant limitations to safety. } \\
\text { V. Unable to eat or drink safely - tube feeding may be considered to } \\
\text { provide nutrition. }\end{array}$ \\
\hline
\end{tabular}

\section{Method}

Observational study design based on retrospective data carried out in educational centres of the Region of Murcia (Spain) between the months of March to June of 2018.

\section{Setting and participants}

Seventy-eight children and adolescents educated in Primary, Secondary Education and Special Education Schools participated in the study. Children had been diagnosed with CP at health centres prior to their schooling and their relevant diagnostic reports were submitted. In all cases, informed consent was obtained from the participants and educational centres that participated in the study.

In Spain, children with $\mathrm{CP}$ and major physical and intellectual disabilities areenrolled in special education centres. Children with mild or moderate physical disabilities, with mild or no intellectual disabilities, are educated in ordinary schools.

Children and adolescents diagnosed with CP aged between 3 and 18 years, educated in schools in the Region of Murcia and who received physical therapy treatment by a pediatric physiotherapist participated in the study. Children diagnosed with neuromotor disorders other than $\mathrm{CP}$, children who had undergone some type of surgery that affected their functional abilities in the 6 months prior to the study or who expressed their intention to relocate from the study area were excluded.

\section{Materials}

All the children were evaluated individually at the schools under the same conditions and recording the following data: 1) Age; 2) GMFCS level; 3) MACS level; 4) EDACS level; 5) CFCS level; 6) CP type according to SCPE. The SCPE classifies this pathology as follows: A) Spastic Unilateral; B) Spastic Bilateral; C) Ataxic; D) Dyskinetic. All the children received Physical Therapy treatment at the schools.

\section{Procedure}

The recruitment, the level of functional abilities in the classification systems and the CP according to the SCPE of the sample subjects were assessed by a physiotherapist blinded to the objectives of the study with more than 10 years of experience according to medical reports available in schools and the available manuals for the different scales.

\section{Statistical analysis}

Descriptive statistics, using the absolute frequencies and percentages in the case of the qualitative variables, and maximum, minimum and mean values of the standard deviation for the quantitative variable "age" were used to describe the results. To evaluate the degree of association between the GMFCS, MACS, CFCS, and EDACS, the Spearman correlation test was used. The significance level was set at $5 \%$. In those cases, with more than $20 \%$ of the expected frequencies having a value above 5 , the likelihood ratio test (LRT) was used as a comparative statistic. Data analysis was performed using the statistical package SPSS, version 20.0.

\section{Results}

The study involved fifty-two Primary and Secondary Schools and two Special Education Schools. The average age was 11.14 (SD 4.44) years, with a minimum of 3 years and a maximum of 18 years. A total of $60.3 \%$ of the sample were girls and most participants went to Special Education (33.3\%) and Primary Schools (33.3\%). In relation to the CP classification, $46.2 \%$ represented Spastic Bilateral CP, 35.9\% Spastic Unilateral CP and $14.1 \%$ were classified as Ataxic CP.

A high correlation between the four classifications was found ( $r>$ $0.70, \mathrm{p}<0.01$ ). Table 2 shows the results of the correlation analysis between GMFCS, MACS, CFCS, and EDACS. Correlations between sample subjects for levels and classifications are shown in tables 3-5.

Statistical differences were found in the LRT results between the various scale levels (GMFCS, LRT $=60.47$; MACS, LRT $=34.58, \mathrm{CFCS}$, $\mathrm{LRT}=40.45$, EDACS, LRT $=40.49)$ and the CP type $(\mathrm{p}=0.00)$.

With regard to GMFCS, spastic unilateral CP was concentrated mainly at levels I (24.4\%) and II (10.3\%). Children with bilateral spasticity (23.1\%) needed to be transported in a wheelchair (GMFCS V) or used technical aids for indoor mobility (GMFCS III). Ataxic CP was distributed between levels I-II, IV-V and children with Dyskinetic $\mathrm{CP}$ presented functional limitations classified to levels II-IV.

For manual abilities classified according to MACS, 32\% of spastic unilateral $\mathrm{CP}$ was classified as levels I-II, while spastic bilateral CP was principally distributed at level V (46.2\%). Children with Ataxia presented greater limitations and adaptations in manual abilities according to levels III-V, while dyskinetic CP was classified among levels I-III.

For everyday communication analysed with the CFCS, $25.6 \%$ of children with spastic unilateral CP were classified as level I, while

Table 2. Correlation between GMFCS, MACS, CFCS and EDACS

\begin{tabular}{|c|c|c|c|c|}
\hline & GMFCS & MACS & CFCS & EDACS \\
\hline GMFCS & 1 & & & \\
\hline MACS & 0.82 & 1 & & \\
\hline CFCS & 0.74 & 0.81 & 1 & \\
\hline EDACS & 0.80 & 0.84 & 0.85 & 1 \\
\hline
\end{tabular}

$\mathrm{r} \geq 0.8$ very high correlation; $0.6 \geq \mathrm{r}<0.8$ high correlation; $0.4 \geq \mathrm{r}<0.6$ moderate correlation; $0.2 \geq \mathrm{r}<0.4$ weak correlation; $\mathrm{r}<0.2$ very weak correlation 
Montero-Mendoza S, Calvo Muñoz I (2019) Analysis of relationship among the functional classification systems in cerebral palsy and the different types according to the Surveillance of Cerebral Palsy in Europe

Table 3. Correlation levels between GMFCS and MACS, CFCS and EDACS.

\begin{tabular}{|c|c|c|c|c|c|c|c|c|c|c|c|c|c|c|c|c|}
\hline GMFCS & & & MACS & & & & & CFCS & & & & & EDACS & & & GMFCS \\
\hline LEVEL & I & II & III & IV & V & I & II & III & IV & V & I & II & III & IV & V & Total \\
\hline I & $25.6 \%$ & $9 \%$ & $1.3 \%$ & $0 \%$ & $0 \%$ & $33.3 \%$ & $2.6 \%$ & $0 \%$ & $0 \%$ & $0 \%$ & $35.9 \%$ & $0 \%$ & $0 \%$ & $0 \%$ & $0 \%$ & $35.9 \%$ \\
\hline II & $3.8 \%$ & $7.7 \%$ & $3.8 \%$ & $1.3 \%$ & $0 \%$ & $3.8 \%$ & $6.4 \%$ & $3.8 \%$ & $1.3 \%$ & $1.3 \%$ & $10.3 \%$ & $5.1 \%$ & $1.3 \%$ & $0 \%$ & $0 \%$ & $16.6 \%$ \\
\hline III & $1.3 \%$ & $6.4 \%$ & $2.6 \%$ & $1.3 \%$ & $0 \%$ & $5.1 \%$ & $2.6 \%$ & $2.6 \%$ & $1.3 \%$ & $0 \%$ & $7.7 \%$ & $3.8 \%$ & $0 \%$ & $0 \%$ & $0 \%$ & $11.5 \%$ \\
\hline IV & $1.3 \%$ & $0 \%$ & $5.1 \%$ & $0 \%$ & $0 \%$ & $2.6 \%$ & $0 \%$ & $1.3 \%$ & $0 \%$ & $2.6 \%$ & $2.6 \%$ & $2.6 \%$ & $1.3 \%$ & $0 \%$ & $0 \%$ & $6.5 \%$ \\
\hline V & $0 \%$ & $2.6 \%$ & $1.3 \%$ & $7.7 \%$ & $17.9 \%$ & $2.6 \%$ & $3.8 \%$ & $0 \%$ & $2.6 \%$ & $20.5 \%$ & $1.3 \%$ & $6.4 \%$ & $3.8 \%$ & $12.8 \%$ & $5.1 \%$ & $29.5 \%$ \\
\hline TOTAL & $32 \%$ & $25.7 \%$ & $14.1 \%$ & $10.3 \%$ & $17.9 \%$ & $44.8 \%$ & $15.4 \%$ & $6 \%$ & $7.7 \%$ & $24.4 \%$ & $57.8 \%$ & $17.9 \%$ & $6.4 \%$ & $12.8 \%$ & $5.1 \%$ & $100 \%$ \\
\hline
\end{tabular}

Table 4. Correlation levels between MACS and CFCS and EDACS

\begin{tabular}{|c|c|c|c|c|c|c|c|c|c|c|}
\hline \multirow{2}{*}{$\begin{array}{l}\text { MACS } \\
\text { LEVEL }\end{array}$} & \multicolumn{5}{|c|}{ CFCS } & \multicolumn{5}{|c|}{ EDACS } \\
\hline & I & II & III & IV & $\mathbf{V}$ & I & II & III & IV & $\mathbf{V}$ \\
\hline I & $28.2 \%$ & $3.8 \%$ & $0 \%$ & $0 \%$ & $0 \%$ & $32.1 \%$ & $0 \%$ & $0 \%$ & $0 \%$ & $0 \%$ \\
\hline II & $15.4 \%$ & $6.4 \%$ & $3.8 \%$ & $0 \%$ & $0 \%$ & $19.2 \%$ & $6.4 \%$ & $0 \%$ & $0 \%$ & $0 \%$ \\
\hline III & $3.8 \%$ & $2.6 \%$ & $1.3 \%$ & $2.5 \%$ & $3.7 \%$ & $6.4 \%$ & $6.4 \%$ & $1.3 \%$ & $0 \%$ & $0 \%$ \\
\hline IV & $0 \%$ & $1.3 \%$ & $2.6 \%$ & $1.3 \%$ & $5.1 \%$ & $0 \%$ & $3.8 \%$ & $5.1 \%$ & $1.3 \%$ & $0 \%$ \\
\hline $\mathrm{V}$ & $0 \%$ & $1.3 \%$ & $0 \%$ & $1.3 \%$ & $15.4 \%$ & $0 \%$ & $1.3 \%$ & $0 \%$ & $11,5 \%$ & $5.1 \%$ \\
\hline TOTAL & $47.4 \%$ & $15.4 \%$ & $7.7 \%$ & $5.1 \%$ & $24.2 \%$ & $57.7 \%$ & $17.9 \%$ & $6.4 \%$ & $12.8 \%$ & $5.1 \%$ \\
\hline
\end{tabular}

Table 5. Correlation levels between CFCS and EDACS

\begin{tabular}{|c|c|c|c|c|c|}
\hline CFCS & \multicolumn{5}{|c|}{ EDACS } \\
\hline LEVEL & I & II & III & IV & V \\
\hline I & $44.9 \%$ & $2.6 \%$ & $0 \%$ & $0 \%$ & $0 \%$ \\
\hline II & $7.7 \%$ & $7.6 \%$ & $0 \%$ & $0 \%$ & $0 \%$ \\
\hline III & $3.8 \%$ & $2.6 \%$ & $1.3 \%$ & $0 \%$ & $0 \%$ \\
\hline IV & $1.3 \%$ & $1.3 \%$ & $1.3 \%$ & $1.3 \%$ & $0 \%$ \\
\hline V & $0 \%$ & $3.8 \%$ & $3.8 \%$ & $11.5 \%$ & $5.1 \%$ \\
\hline TOTAL & $57.7 \%$ & $17.8 \%$ & $6.4 \%$ & $12.8 \%$ & $5.1 \%$ \\
\hline
\end{tabular}

6.4\% were slower paced (CFCS II). Similar results were found for spastic bilateral $\mathrm{CP}$ and ataxic $\mathrm{CP}$, while dyskinetic $\mathrm{CP}$ was distributed proportionally between levels I, II and V.

In terms of feeding abilities and CP types, $34.6 \%$ of children with spastic unilateral CP were able to eat and drink safely and effectively (EDACS I), while those with spastic bilateral CP were distributed mainly among levels I, II and IV respectively; $5.1 \%$ of the children with ataxic CP had limitations in the effectiveness (EDAC II), while the results for dyskinetic CP was similar in levels I-III.

\section{Discussion}

To our knowledge, this is the first study in Spain that assesses the relationship between scales used in children with $\mathrm{CP}$ as well as their distribution among the different $\mathrm{CP}$ types according to the SCPE.

The study revealed a high correlation among the scales. Several studies have described different correlations between the GMFCS and the MACS. Carnahan et al. [19] found a poor correlation between these two scales and varying degrees of association between gross motor function and manual ability in different $\mathrm{CP}$ types. The Kappa statistic was used in this study and this might explain the results obtained, as this coefficient indicates the relation of a single scale in different investigations, while the Spearman correlation coefficient evaluates the association between two random variables, this being one of the objectives of this study. Gunel et al. [20] found a high correlation in a sample of 185 children with CP and confirmed the association between the two scales. Similar results relating the GMFCS and MACS with CFCS were found $[21,22]$.
The distribution of the sample among GMFCS and MACS levels revealed that the majority of children able to walk without restrictions, likewise, had no limitations in their manual abilities. The opposite result was found for lower levels of functionality on the two scales. These results are consistent with other studies carried out Compagnone et al. [22] and Lee et al. [23].

The results for the GMFCS and the CFCS were similar to those obtained in the above case. However, children with walking limitations presented a greater variability in communication abilities (levels II-IV in the CFCS). It may be argued that limitations affecting coordination and balance present in the more advanced motor activities might also affect the rhythm of the communication, whereby more time is needed to understand and produce messages as well as to amend mistakes, especially in dynamic situations.

The analysis between the GMFCS and EDACS showed that most of the children who did not have limitations or had problems with speed or walking long distances (GMFCS I-II), fed and drank safely and efficiently (EDACS I). On the other hand, all the children who presented major limitations on feeding and drinking (EDACS IV-V) needed to be transported in a wheelchair (GMFCS V). These results reinforce the relationship between the ability to maintain the alignment of different parts of the body (especially head and trunk) as well as their motor control and functionality in feeding activities. Alterations in postural control favour the development of pathological postures in the orofacial zone, head and spine that hinder feeding activities. Bacco et al. [24] support the need to provide a communication tool between the various professionals working with child and family.

The results obtained for the MACS and the CFCS revealed that children with difficulties in manipulation and needing help (MACS II-IV) showed greater variability in communication skills. The CFCS contemplates gestures, behaviours and the possibility of using alternative communication systems as a way of communicating. All these possibilities can be diminished depending on the child's manual abilities in daily life activities.

Analysis of the relationship between MACS and EDACS found a proportional relationship between the first and last levels. Children classified as levels IV-V most likely present neuromuscular alterations 
Montero-Mendoza S, Calvo Muñoz I (2019) Analysis of relationship among the functional classification systems in cerebral palsy and the different types according to the Surveillance of Cerebral Palsy in Europe

affecting the orofacial zone and the voluntary control of the extremities, so they will need assistance and / or adapted cutlery in order to attain the necessary manual skills at the time of feeding. Similar results were found when analysing the CFCS and the EDACS at the different levels.

Taking into account the functional alterations described in the last levels of the functional classifications and the results obtained in this study, children classified from level III onwards and mainly presenting an overall involvement with limitation of movements and posture (present in all spastic PC and dyskinetic cases) will develop problems affecting their ability to move independently, or even with technical aids, to move from a sitting to a standing position and will need additional support to maintain functional seating. In addition, they will have greater difficulties to maintain the alignment and control of the head and trunk and therefore manual activities, communication and feeding will be challenged. These difficulties justify the need to make available to these children the assessment, treatment and follow-up by the various professionals of the rehabilitation services of their area and, therefore, to improve their independence and quality of life.

Regarding the second objective of our study, spastic unilateral CP cases were mainly distributed between the first two levels of the GMFCS and MACS. In the case of MACS, children's manual ability is less affected than the gross motor function, using the hand of the healthy upper extremity to perform different activities or tasks. The reasons behind these results have also been discussed in other studies $[19,20]$. Children with dyskinetic CP showed a profile of global alteration that affected both gross motor functions and manual ability.

In the case of spastic bilateral $\mathrm{CP}$, the results revealed a greater distribution among different levels in GMFCS and MACS, with a greater number of cases in level $\mathrm{V}$. These results can be explained by the varying degree of involvement presented in children with spatisc bilateral CP: children with greater involvement of the trunk and lower extremities and children with severe involvement of all four extremities. Montero et al. [25] confirmed this hypothesis with a sample of 139 children with $\mathrm{CP}$ in which the gross motor function and postural control in sitting posture were analysed. Although the use of CP classification according to the SCPE does not allow to differentiate between these two types of CP according to the Swedish nomenclature, in clinical practice it is difficult to differentiate between a diparesia and a spastic tetraparesis, so we agree with Beckung et al. [26] and Himmelmann et al. [27] in that the traditional classification does not provide enough information on motor development. Children with ataxic CP were distributed among different levels in the GMFCS and MACS.

In the case of dyskinetic $\mathrm{CP}$, the results of our study show a greater involvement of gross motor skills than of manual skills (GMFCS II-IV, MACS I-III). Dyskinetic CP includes dystonic CP (greater involvement in the orofacial zone without affecting the masticatory system or swallowing functions, and proximal muscles of the upper extremities), which would be represented in the levels of greater functionality, and choreoathetoid CP, which is characterised by the presence of greater involuntary movements and therefore entailing greater difficulties in the gross motor function and manual abilities.

In relation to the CFCS, spastic unilateral CP for the most part presented no communication problems and spastic bilateral CP showed greater variability in terms of communication possibilities.

To our knowledge, this is the first study that analyses $\mathrm{CP}$ classification according to SCPE with the EDACS. In the case of spastic unilateral $\mathrm{CP}$, the results confirm the hypothesis for these children (in most cases classified as level I of the EDACS), because they usually present no alterations in orofacial motor abilities and, therefore, most limitations mainly affect manual ability. In the case of spastic bilateral $\mathrm{CP}$, the difference between children suffering a greater involvement of the trunk and the lower extremities and children with severe involvement of all four extremities is more significant than that found in the results for the other classification systems. The sample of this study has been distributed mainly among levels I and II (children with impaired trunk and lower extremities) and levels IV and V (children with impaired trunk and all four extremities). The results for ataxic CP fail to provide accurate information thus preventing a reliable prognosis of functional abilities. The result for dyskinetic CP is similar to that obtained in the previous cases.

\section{Study limitations}

In relation to the limitations of the study, the results shown come from a small sample, and therefore such sample cannot be assumed to be representative of the general population, hence the results must be interpreted with caution. In addition, a large number of children from special schools with severe motor impairment have been included and therefore classified in the last levels along with spastic bilateral $\mathrm{CP}$ cases, so it has not been possible to obtain proportional results in relation to the functional abilities assessed by the classification systems.

\section{Conclusion}

The GMFCS, MACS, CFCS and EDACS are very useful in clinical practice to describe the functional profile in children and adolescents with CP. In addition, the functional classification systems present a predictive factor for some CP types such as spastic unilateral CP, with higher levels of functional abilities and spatic bilateral $\mathrm{CP}$, differentiating between children with greater involvement of the trunk and lower extremities and children with severe involvement of all four extremities.

\section{Acknowledgements}

We want to thank all the participating educational centers and especially the Physiotherapists who work in the Ministry of Education of the Region of Murcia (Spain).

\section{Ethical approval}

All procedures performed in studies involving human participants were in accordance with the ethical standards of the institutional and/ or national research committee and with the 1964 Helsinki declaration and its subsequent amendments or comparable ethical standards. This article does not include any studies performed on animals by any of the authors.

\section{Conflict of interest}

\section{None}

\section{Funding}

This research did not receive any specific grant from funding agencies in the public, commercial, or not-for-profit sectors.

\section{References}

1. Bax MC (1962) Terminology and classification of cerebral palsy. Dev Med Child Neurol 6: 295-297. [Crossref]

2. Rosenbaum P, Paneth N, Leviton A, Goldstein M, Bax M, et al. (2007) A report: the definition and classification of cerebral palsy. Dev Med Child Neurol 109: 8-14. [Crossref] 
Montero-Mendoza S, Calvo Muñoz I (2019) Analysis of relationship among the functional classification systems in cerebral palsy and the different types according to the Surveillance of Cerebral Palsy in Europe

3. Sankar C, Mundkur N (2005) Cerebral palsy-definition, classification, etiology and early diagnosis. Indian J Pediatr 72: 865-868. [Crossref]

4. Phipps S, Roberts P (2012) Predicting the Effects of Cerebral Palsy Severity on SelfCare, Mobility, and Social Function. Am J Occup Ther 66: 422-429. [Crossref]

5. Saxena S, Orley J (1997) Quality of life assessment: The World Health Organization perspective. Eur Psychiatry 12: 263-266. [Crossref]

6. Rethlefsen SA, Ryan DD, Kay RM (2010) Classification systems in cerebral palsy. Orthop Clin North A 41: 457-67. [Crossref]

7. Morton R, Wheatley R, Minford J (1999) Respiratory tract infections due to direct and reflux aspiration in children with severe neurodisability. Dev Med Child Neurol 41: 329-334. [Crossref]

8. Cass H, Wallis C, Ryan M, Reilly S, McHugh K (2005) Assessing pulmonary consequences of dysphagia in children with neurological disabilities: when to intervene? Dev Med Child Neurol 47: 347-352. [Crossref]

9. Odding E, Roebroeck ME, Stam HJ (2009) The epidemiology of cerebral palsy: Incidence, impairments and risk factors. Disabil Rehabil 28: 183-191. [Crossref]

10. Reddihough DS, Collins KJ (2003) The epidemiology and causes of cerebral palsy. Aust J Physiother 49: 7-12. [Crossref]

11. Rosenbaum P, Eliasson AC, Hidecker MJ, Palisano RJ (2014) Classification in childhood disability: focusing on function in the 21st century. J Child Neurol 29: 10361045. [Crossref]

12. Palisano R, Rosenbaum P, Walter S, Russell D, Wood E, et al. (1997) Development and reliability of a system to classify gross motor function in children with cerebral palsy. Dev Med Child Neurol 39: 214-223. [Crossref]

13. Eliasson AC, Krumlinde-Sundholm L, Rosblad B, Beckung E, Arner M, et al. (2006) The Manual Ability Classification System (MACS) for children with cerebral palsy: scale development and evidence of validity and reliability. Dev Med Child Neurol 48: 549-554. [Crossref]

14. Hidecker MJC, Paneth N, Rosenbaum PL, Kent RD, Lillie J, et al (2011) Developing and validating the Communication Function Classification System (CFCS) for individuals with cerebral palsy. Dev Med Child Neurol 53: 704-710. [Crossref]

15. Sellers D, Mandy A, Pennington L, Hankins M, Morris C (2014) Development and reliability of a system to classify eating and drinking ability of people with cerebral palsy. Dev Med Child Neurol 56: 245-251. [Crossref]

16. Gainsborough M, Surman G, Maestri G, Colver A, Cans C (2008) Validity and reliability of the guidelines of the surveillance of cerebral palsy in Europe for the classification of cerebral palsy. Dev Med Child Neurol 50: 828-831. [Crossref]
17. Surveillance of Cerebral Palsy in Europe (SCPE) (2000) Surveillance of cerebral palsy in Europe: A collaboration of cerebral palsy surveys and registers. Dev Med Child Neurol 42: 816-824. [Crossref]

18. Surveillance of Cerebral Palsy in Europe (SCPE) (2002) Prevalence and characteristics of children with cerebral palsy in Europe. Dev Med Child Neurol 44: 633-640. [Crossref]

19. Carnahan KD, Arner M, Hägglund G (2007) Association between gross motor function (GMFCS) and manual ability (MACS) in children with cerebral palsy. A populationbased study of 359 children. BMC Musculoskelet Disord 21: 50. [Crossref]

20. Gunel MK, Mutlu A, Tarsuslu T, Livanelioglu A (2009) Relationship among the Manual Ability Classification System (MACS), the Gross Motor Function Classification System (GMFCS), and the functional status (WeeFIM) in children with spastic cerebral palsy. A population-based study of 359 children. Eur J Pediatr 168: 477-485. [Crossref]

21. Hidecker MJC, Ho NT, Dodge N, Hurvitz EA, Slaughter J, et al (2012) Interrelationships of functional status in cerebral palsy: analyzing gross motor function, manual ability, and communication function classification systems in children. Dev Med Child Neurol 54: 737. [Crossref]

22. Compagnone E, Maniglio J, Camposeo S, Vespino T, Losito L, et al. (2014) Functional classifications for cerebral palsy: correlations between the Gross motor function classification system (GMFCS), the manual ability classification system (MACS) and the communication function classification system (CFCS). Res Dev Disabil 35: 26512657. [Crossref]

23. Lee JW, Chung EJ, Lee BH (2015) A comparison of functioning, activity, and participation in school-aged children with cerebral palsy using the manual ability classification system. J Phys Ther Sci 27: 2611-2614. [Crossref]

24. Bacco JL, Araya CF, Flores GE, Peña JN (2014) Trastornos de la alimentación y deglución en niños y jóvenes portadores de parálisis cerebral: abordaje multidisciplinario. Rev Med Clin Condes 25: 330-342.

25. Montero S, Gómez-Conesa A, Hidalgo MD (2015) Association between gross motor function and postural control in sitting in children with Cerebral Palsy: a correlational study in Spain. BMC Pediatrics 15: 124. [Crossref]

26. Beckung E, Carlsson G, Carlsdotter S, Uvebrant P (2007) The natural history of gross motor development in children with cerebral palsy aged 1 to 15 years. Dev Med Child Neurol 49: 751-756. [Crossref]

27. Himmelmann K, Beckung E, Hagberg G, Uvebrant P (2006) Gross and fine motor function and accompanying impairments in cerebral palsy. Dev Med Child Neurol 48: 417-423. [Crossref]

Copyright: (C2019 Montero-Mendoza S. This is an open-access article distributed under the terms of the Creative Commons Attribution License, which permits unrestricted use, distribution, and reproduction in any medium, provided the original author and source are credited. 